\title{
HUBUNGAN JUMLAH KUNJUNGAN POSYANDU DENGAN STATUS GIZI BALITA (1-5 TAHUN)
}

\author{
Wahyudi Diagama ${ }^{1}$, Yufitriana Amir ${ }^{2}$, Yesi Hasneli ${ }^{3}$ \\ ${ }_{1,2,3}$ Program Studi Ilmu Keperawatan \\ Universitas Riau \\ Email: wahyudidiagama@gmail.com
}

\begin{abstract}
Abstrak
Penimbangan berat badan anak setiap bulan untuk mengetahui status gizi anak merupakan salah satu kegiatan rutin di Posyandu. Salah satu upaya untuk mengurangi masalah gizi buruk pada anak adalah meningkatkan partisipasi ibu dalam mengunjungi dan menimbang balitanya ke Posyandu setiap bulan. Penelitian ini bertujuan untuk mengetahui hubungan jumlah kunjungan Posyandu dengan status gizi balita (1-5 tahun). Penelitian ini menggunakan desain deskriptif korelasi dengan pendekatan retrospektif. Penelitian dilakukan di wilayah kerja Puskesmas Payung Sekaki dengan jumlah sampel 382 ibu dan anak balita dengan menggunakan teknik proporsional random sampling berdasarkan jumlah Posyandu. Alat ukur yang digunakan adalah kuesioner untuk data demografi dan buku registrasi penimbangan berat badan anak. Analisa yang digunakan adalah analisa univariat untuk mengetahui distribusi frekuensi dan analisa bivariat menggunakan chi-square. Hasil penelitian menunjukan responden yang rutin mengunjungi Posyandu sebanyak 145 orang (38\%) dan tidak rutin mengunjungi Posyandu sebanyak 237 orang (62\%). Anak yang memiliki status gizi baik sebanyak 203 orang $(53,1 \%)$, gizi kurang sebanyak 109 orang $(28,5 \%)$, dan gizi buruk sebanyak 70 orang $(18,3 \%)$. Hasil analisa bivariat didapatkan $p$ value $(0,00)<a(0,05)$, sehingga dapat disimpulkan ada hubungan jumlah kunjungan Posyandu dengan status gizi balita (1-5 tahun). Saran untuk petugas puskesmas agar bisa melakukan pelatihan dan penyuluhan kesehatan kepada kader dan meningkatkan fasilitas kesehatan di Posyandu
\end{abstract}

Kata kunci: Balita, ibu, posyandu, status gizi

\section{Abstract}

Weight balancing activities every month to know the nutritional status of children is one of routine activities in Posyandu. One effort to reduce malnutrition problem in children is increase the participation of mothers to visit and check her children weight to Posyandu every month. This study aims to determine the correlation number of visit Posyandu with nutritional status of children (1-5 years). The design of this research was descriptive correlation with retrospective approach. The research was conducted in Payung Sekaki Health Center Public area with 382 samples of mothers and children using proportional random sampling technique according to number of Posyandu member. The measuring instrument used questionnaire for demographic data and children's weighing registration books. The analysis used univariate analysis to know the frequency distribution and bivariate analysis using chi-square. The results of the research show respondents who regularly visit Posyandu are 145 people (38\%) and do not regularly visit Posyandu as many as 237 people (62\%). Children who have good nutrition status as many as 203 people (53.1\%), malnutrition as many as 109 people (28,5\%), and severe malnutrition of 70 people (18.3\%). The result of bivariate analysis show $p$ value $(0,00)<a(0,05)$, so it can be concluded there is correlation number of visit Posyandu with nutritional status of children (1-5 year). Suggestions for Health Center Public to be albe to conduct health training and counseling to cadres and improve health facilities in Posyandu.

Keywords: Children, mother, posyandu, nutritional status

\section{PENDAHULUAN}

Masyarakat sehat terwujud jika adanya kesadaran setiap anggota masyarakat akan pentingnya perilaku sehat, berkeinginan, serta berdaya untuk hidup sehat. Masyarakat bersinergi membangun kondisi lingkungan yang kondusif untuk hidup sehat dengan pemerintah. Langkah tersebut tercermin dalam 
Wahyudi Diagama', Yufitriana Amir ${ }^{2}$, Yesi Hasneli ${ }^{3}$, Hubungan Jumlah Kunjungan Posyandu dengan Status Gizi Balita (1-5 Tahun)

pengembangan sarana Upaya Kesehatan

Bersumberdaya Masyarakat (UKBM) didesa dan kelurahan, seperti adanya Pos Kesehatan Desa (Poskesdes) dan Pos Pelayanan Terpadu (Posyandu) (Dinas Kesehatan Provinsi Riau, 2014).

UKBM yang ada didesa dan kelurahan menjadi ciri khas bahwa desa dan kelurahan tersebut telah menjadi desa dan kelurahan siaga aktif. Upaya ini bertujuan agar penduduk didesa dan kelurahan tersebut dapat mengakses dengan mudah pelayanan kesehatan dasar dan mengembangkan UKBM serta melaksanakan kegiatan berbasis masyarakat (pemantauan penyakit, kesehatan ibu dan anak, gizi, lingkungan, dan perilaku), kedaruratan kesehatan dan penanggulangan bencana, serta penyehatan lingkungan sehingga masyarakatnya menerapkan Perilaku Hidup Bersih dan Sehat (PHBS) (Dinas Kesehatan Provinsi Riau, 2014).

Posyandu merupakan salah satu bentuk UKBM yang dikelola dan diselenggarakan dari, oleh, untuk, dan bersama masyarakat untuk memberdayakan dan memberikan kemudahan kepada masyarakat dalam memperoleh pelayanan kesehatan dasar bagi masyarakat terutama ibu, bayi, dan anak balita. Posyandu diharapkan dapat melaksanakan fungsinya dalam lima program utama, yaitu kesehatan ibu dan anak, keluarga berencana, imunisasi, gizi, pencegahan dan penanggulangan diare (Dinas Kesehatan Provinsi Riau, 2015).
Data Kementerian Kesehatan RI (2015), jumlah Posyandu di Indonesia ada sebanyak 266.827 dan jumlah kader sekitar 3 sampai 4 orang setiap per Posyandu. Di Provinsi Riau, jumlah Posyandu mengalami penurunan dari 5.138 pada tahun 2014 menjadi 4.772 pada tahun 2015, sedangkan di Pekanbaru, jumlah Posyandu juga mengalami penurunan dari 614 pada tahun 2014 menjadi 609 pada tahun 2015. Penyebab penurunan jumlah Posyandu karena partisipasi masyarakat sedikit untuk menjadi kader Posyandu dan masyarakat yang kurang kompeten (Dinas Kesehatan Provinsi Riau, 2015).

Setiap bulannya Posyandu melakukan kegiatan penimbangan berat badan balita dan hasilnya dicatat dalam buku Kartu Menuju Sehat (KMS). Pencatatan di KMS bertujuan untuk mengetahui hasil penimbangan apakah grafik pertumbuhan anak naik, turun, tetap dan berada garis hijau tua, garis hijau muda, digaris kuning atau dibawah garis merah. Penimbangan anak setiap bulan dapat diketahui kecenderungan perubahan status gizi anak (Sulistyorini, 2010).

Cakupan penimbangan balita di Indonesia mengalami penurunan dari $80,8 \%$ tahun 2014 menjadi 73,0\% tahun 2015 (Kementerian Kesehatan RI, 2015). Di Provinsi Riau, cakupan penimbangan balita di Posyandu sedikit mengalami penurunan dari 64,7\% tahun 2014 menjadi 62,2\% tahun 2015. Di Pekanbaru, cakupan penimbangan balita di Posyandu juga mengalami penurunan dari 
77,5\% tahun 2014 menjadi 73,3\% tahun 2015

(Dinas Kesehatan Provinsi Riau, 2015).

Posyandu salah satu tujuannya untuk memantau pertumbuhan dan peningkatan status gizi anak balita karena Posyandu punya 5 program utama. Hal ini bisa tercapai jika ibu yang memiliki anak balita aktif dalam kegiatan Posyandu setiap bulan untuk ditimbang dan dipantau pertumbuhan dan perkembangannya. Penimbangan balita secara berkala tiap bulan dapat mendeteksi sedini mungkin penyimpangan pada pertumbuhan dan perkembangan balita tersebut, seperti kejadian gizi buruk pada anak balita. Gizi buruk menyebabkan terjadinya penyimpangan pertumbuhan dan perkembangan dan harus cepat ditangani agar angka kesakitan dan kematian pada balita berkurang (Sulistyawati, 2014).

Kasus gizi buruk pada balita di Indonesia pada tahun 2015 secara nasional sebanyak 26.518 mengalami penurunan dibandingkan tahun 2014 sebanyak 32.521. Kasus gizi buruk yang dimaksud ditentukan berdasarkan perhitungan berat badan menurut tinggi badan balita (Kementerian Kesehatan RI, 2015).

Data status gizi anak di Provinsi Riau, jumlah balita dengan berat badan di Bawah Garis Merah (BGM) mengalami peningkatan dari 2.547 anak tahun 2014 menjadi 4.903 anak tahun 2015, dan jumlah balita gizi buruk sedikit menurun dari 155 anak tahun 2014 menjadi 150 anak tahun 2015. Di Pekanbaru, jumlah berat badan balita BGM mengalami
Jurnal Ners Indonesia, Vol. 9, No. 2, Maret 2019 peningkatan dari 429 anak tahun 2014 menjadi 661 anak tahun 2015, dan jumlah balita gizi buruk tahun 2014-2015 sebanyak 12 anak (Dinas Kesehatan Provinsi Riau, 2015).

Hal ini membuat balita menjadi salah satu sasaran Posyandu yang cukup penting dibandingkan anak usia lainnya (Maryunani, 2010). Apabila anak mengalami gizi buruk, mengakibatkan pertumbuhan dan perkembangan anak terhambat, menurunkan daya tahan tubuh, dan memperlambat pembentukan sel otak sehingga berpengaruh pada kecerdasan anak (Dewi dkk, 2013).

Partisipasi ibu harus ditingkatkan dalam upaya untuk mengurangi masalah gizi buruk pada anak dengan mengunjungi dan menimbang balitanya ke Posyandu setiap bulan (Kementerian Kesehatan RI, 2015). Hal ini diperkuat dengan penelitian Octaviani dkk (2008), tentang hubungan keaktifan keluarga dalam kegiatan Posyandu dengan status gizi balita, didapatkan bahwa ada hubungan yang signifikan antara keaktifan keluarga ke Posyandu dengan status gizi balita ( $p$ value 0,00). Penelitian Tunjungsari (2010), tentang hubungan antara keaktifan kunjungan ibu ke Posyandu dengan perkembangan status gizi anak usia 6-23 bulan, didapatkan bahwa keaktifan kunjungan ibu ke Posyandu juga mempengaruhi status gizi anak ( $p$ value 0,02 ).

Kunjungan balita ke Posyandu yang paling baik adalah rutin setiap bulan atau 12 kali per tahun, kunjungan 8 kali atau lebih dalam kurun waktu satu tahun dianggap rutin, dan kunjungan kurang dari 8 kali per tahun 
Wahyudi Diagama', Yufitriana Amir ${ }^{2}$, Yesi Hasneli ${ }^{3}$, Hubungan Jumlah Kunjungan Posyandu dengan Status Gizi Balita (1-5 Tahun)

dianggap tidak rutin (Dinas Kesehatan Provinsi Jawa Tengah, 2013). Ibu yang datang ke Posyandu akan diberi penyuluhan terkait kesehatan ibu dan anak oleh tenaga kesehatan dari Puskesmas, sehingga dapat meningkatkan pemahaman ibu tentang status gizi, pertumbuhan dan perkembangan anaknya (Kementerian Kesehatan RI, 2012).

Kerutinan ibu dalam mengunjungi Posyandu akan sangat bermanfaat sebagai monitoring berat badan untuk mengetahui status gizi anak dengan menimbang berat badan setiap bulan agar dapat secara dini mendeteksi terhadap status kesehatan anak, sehingga dapat segera ditentukan intervensi lebih lanjut. Apabila ibu tidak secara rutin mengunjungi Posyandu mengakibatkan status gizi anak tidak terpantau dengan baik (Astuti \& Rivqoh, 2010).

Studi pendahuluan yang dilakukan peneliti di Posyandu Mawar, di wilayah kerja Puskesmas Payung Sekaki Kelurahan Tampan pada tanggal 07 Maret 2017, pada 10 orang tua yang membawa balitanya ke Posyandu, 4 orang tua rutin mengunjungi Posyandu dengan berat badan anaknya naik, dan 6 orang tua tidak rutin mengunjungi Posyandu, berat badan anaknya tetap bahkan mengalami penurunan. Ketidakrutinan kunjungan ibu yang kurang dari 8 kali dalam setahun ke Posyandu, mengatakan karena ada kesibukan dirumah, menjemput anak ke sekolah, lupa jadwal Posyandu, anak yang menolak dibawa ke Posyandu sehingga tidak bisa datang ke Posyandu. Berdasarkan uraian diatas, peneliti tertarik untuk melakukan penelitian tentang hubungan jumlah kunjungan Posyandu dengan status gizi balita.

\section{MANFAAT PENELITIAN}

Hasil penelitian ini diharapkan dapat memberikan informasi dalam pengembangan ilmu pengetahuan tentang hubungan jumlah kunjungan Posyandu dengan status gizi balita (1-5 tahun).

\section{METODE PENELITIAN}

Penelitian ini dilakukan di wilayah kerja Puskesmas Payung Sekaki, Kota Pekanbaru yang dimulai dari bulan Februari sampai bulan Juli 2017. Penelitian ini merupakan jenis penelitian kuantitatif yang menggunakan desain penelitian deskriptif korelasi dengan pendekatan retrospektif. Rancangan ini menghubungkan variabel yang satu dengan variabel yang lainnya, selanjutnya mengujinya secara statistik (uji hipotesis) atau dikenal dengan uji korelasi yang menghasilkan koefisien korelasi (Swarjana, 2012).

Populasi penelitian ini adalah seluruh ibu dan balita di wilayah kerja Puskesmas Payung Sekaki yang berjumlah 8.300 balita (1-5 tahun). Perhitungan sampel didapatkan sebanyak 382 orang responden dan teknik pengambilan sample dalam penelitian ini dilakukan secara proporsional random sampling berdasarkan jumlah Posyandu.

Alat pengumpulan data yang digunakan dalam penelitian ini adalah kuesioner untuk 
data demografi responden dan buku registrasi catatan penimbangan berat badan balita.

Analisa data menggunakan analisa univariat untuk mendeskripsikan karakteristik responden terkait (umur ibu, umur anak, jenis kelamin anak, pendidikan terakhir ibu, pekerjaan ibu, dan pendapatan keluarga dalam sebulan), jumlah kunjungan ibu ke Posyandu, dan status gizi balita. Analisa bivariat untuk mengetahui hubungan jumlah kunjungan Posyandu dengan status gizi balita dengan menggunakan uji chi-square.

\section{HASIL PENELITIAN}

\section{Analisa univariat}

Karakteristik responden seperti umur ibu, umur anak, jenis kelamin anak, pendidikan, pekerjaan, pendapatan keluarga dan status gizi anak, disajikan pada tabel 1 .

Tabel 1

Distribusi frekuensi karakteristik responden

\begin{tabular}{lcc}
\hline Karakteristik & Jumlah & $\begin{array}{l}\text { Persentase } \\
(\%)\end{array}$ \\
\hline Umur Ibu (tahun): & & \\
$17-25$ & 43 & 11,3 \\
$26-35$ & 327 & 85,6 \\
$36-45$ & 12 & 3,1 \\
\hline Umur Anak & & \\
(bulan): & 114 & 29,8 \\
$12-24$ & 184 & 48,2 \\
$25-36$ & 52 & 13,6 \\
$37-48$ & 32 & 8,4 \\
$49-60$ & & \\
\hline Jenis Kelamin & & \\
Anak: & 204 & 53,4 \\
a. Laki-laki & 178 & 46,6 \\
b. Perempuan & & \\
\hline Pendidkan: &
\end{tabular}

\section{Pendidikan:}

\begin{tabular}{llcc} 
a. SD & 1 & 0,3 \\
b. & SMP & 46 & 12 \\
c. SMA & 325 & 85,1 \\
d. & Diploma & 7 & 1,8 \\
e. & S1 & 3 & 0,8 \\
\hline
\end{tabular}

\begin{tabular}{|c|c|c|}
\hline $\begin{array}{l}\text { Pekerjaan: } \\
\text { a. Ibu rumah tangga } \\
\text { (IRT) } \\
\text { b. Wiraswasta }\end{array}$ & $\begin{array}{c}347 \\
35\end{array}$ & $\begin{array}{c}90,8 \\
9,2\end{array}$ \\
\hline $\begin{array}{l}\text { Pendapatan } \\
\text { Keluarga: } \\
\text { a. } 500.000- \\
1.500 .000 \\
\text { b. } 2.000 .000- \\
\\
3.000 .000\end{array}$ & $\begin{array}{l}235 \\
147\end{array}$ & $\begin{array}{l}61,5 \\
38,5\end{array}$ \\
\hline $\begin{array}{ll}\text { Status Gizi } \\
\text { (BB/Umur): } \\
\text { a. } & \text { Gizi Baik (-2 SD } \\
& \text { s.d } 2 \text { SD) } \\
\text { b. } & \text { Gizi Kurang (-3 } \\
& \text { SD s.d <-2 SD) } \\
\text { c. } & \text { Gizi Buruk (<-3 } \\
& \text { SD) } \\
\end{array}$ & $\begin{array}{c}203 \\
109 \\
70\end{array}$ & $\begin{array}{l}53,1 \\
28,5 \\
18,3\end{array}$ \\
\hline Total & 382 & 100 \\
\hline
\end{tabular}

Tabel 1 menggambarkan bahwa mayoritas umur ibu berada pada rentang 2635 tahun sebanyak 327 orang (85,6\%). Responden anak mayoritas berumur pada rentang 25-36 bulan sebanyak 184 orang $(48,2 \%)$ dengan berjenis kelamin laki-laki sebanyak 204 orang (53,4\%). Responden ibu mayoritas berpendidikan SMA sebanyak 325 orang $(85,1 \%)$ dengan status pekerjaan sebagai ibu rumah tangga (IRT) sebanyak 347 orang $(90,8 \%)$. Pendapatan keluarga dalam sebulan 500.000-1.500.00 sebanyak 235 orang $(61,5 \%)$ dengan anak berstatus gizi baik sebanyak 203 $(53,1 \%)$.

Tabel 2

Distribusi frekuensi kunjungan ke Posyandu

\begin{tabular}{lcc}
\hline \multicolumn{1}{c}{ Variabel } & Jumlah & $\begin{array}{c}\text { Persentase } \\
(\%)\end{array}$ \\
\hline $\begin{array}{l}\text { Kunjungan ke posyandu: } \\
\text { a. } \begin{array}{l}\text { Rutin (kunjungan ibu } \\
\text { ke posyandu } \geq 8 \text { kali } \\
\text { dalam satu tahun } \\
\text { terakhir) }\end{array}\end{array}$ & 145 & 38,0 \\
b. $\begin{array}{l}\text { Tidak rutin (kunjungan } \\
\text { ibu ke posyandu }<8 \\
\text { kali dalam satu tahun } \\
\text { terakhir) }\end{array}$ & 237 & 62,0 \\
\hline \multicolumn{1}{c}{ Total } & \\
\hline & 382 & 100 \\
\hline
\end{tabular}


Wahyudi Diagama', Yufitriana Amir ${ }^{2}$, Yesi Hasneli ${ }^{3}$, Hubungan Jumlah Kunjungan Posyandu dengan Status Gizi Balita (1-5 Tahun)

Tabel 2, responden yang tidak membawa anaknya berkunjung ke Posyandu sebanyak 237 orang $(62 \%)$ dan masih ada yang rutin mengunjungi Posyandu sebanyak 145 orang $(38 \%)$.

\section{Analisa Bivariat}

Tabel 3

Hubungan kunjungan Posyandu dengan status gizi balita (1-5 tahun)

\begin{tabular}{|c|c|c|c|c|c|}
\hline \multirow{3}{*}{$\begin{array}{l}\text { Kunjungan } \\
\text { Posyandu }\end{array}$} & \multicolumn{3}{|c|}{ Status Gizi } & \multirow[b]{2}{*}{ Total } & \multirow[b]{2}{*}{$\begin{array}{c}p \\
\text { value }\end{array}$} \\
\hline & $\begin{array}{l}\text { Gizi } \\
\text { Baik }\end{array}$ & $\begin{array}{c}\text { Gizi } \\
\text { Kuran } \\
\text { g }\end{array}$ & $\begin{array}{c}\text { Gizi } \\
\text { Buruk }\end{array}$ & & \\
\hline & $\mathrm{n}(\%)$ & $\mathrm{n}(\%)$ & $\mathrm{n}(\%)$ & n (\%) & \multirow{4}{*}{0,00} \\
\hline Rutin & $\begin{array}{c}100 \\
(69,0)\end{array}$ & $\begin{array}{c}33 \\
(22,8)\end{array}$ & $\begin{array}{c}12 \\
(8,3)\end{array}$ & $\begin{array}{c}145 \\
(100)\end{array}$ & \\
\hline Tidak rutin & $\begin{array}{c}103 \\
(43,5) \\
\end{array}$ & $\begin{array}{c}76 \\
(32,1) \\
\end{array}$ & $\begin{array}{r}58 \\
(24,5) \\
\end{array}$ & $\begin{array}{c}237 \\
(100) \\
\end{array}$ & \\
\hline Total & $\begin{array}{c}203 \\
(53,1) \\
\end{array}$ & $\begin{array}{c}109 \\
(28,5)\end{array}$ & $\begin{array}{c}70 \\
(18,3) \\
\end{array}$ & $\begin{array}{c}382 \\
(100)\end{array}$ & \\
\hline
\end{tabular}

Tabel 3, responden yang rutin mengunjungi posyandu mempunyai gizi baik sebanyak 100 orang $(69,0 \%)$ dan responden yang tidak rutin mengunjungi Posyandu mempunyai gizi baik sebanyak 103 orang (43,5\%). Hasil uji statistik didapatkan $p$ value $(0,00)<a(0,05)$, sehingga dapat disimpulkan ada hubungan jumlah kunjungan Posyandu dengan status gizi balita (1-5 tahun).

\section{PEMBAHASAN}

\section{Karakteristik responden}

\section{a. Umur}

Hasil penelitian menunjukkan mayoritas umur responden yang berkunjung ke posyandu adalah 26-35 tahun yaitu sebanyak 327 orang $(85,6 \%)$ dan mayoritas umur anak adalah 2536 bulan yaitu sebanyak 184 orang (48,2\%). Hal ini sama dengan hasil penelitian Purba (2012), tentang faktor yang berhubungan dengan perilaku kunjungan ke Posyandu pada ibu balita, didapatkan hasil bahwa mayoritas umur ibu yang berkunjung ke Posyandu yaitu rentang umur 26-35 tahun $(63,4 \%)$.

Rentang umur pernikahan bagi perempuan yang disarankan oleh Badan Kependudukan dan Keluarga Berencana Nasional (BKKBN), (2017) yakni pada rentang umur 20-25 tahun karena pada umur ini sudah matang secara biologis dan psikologis serta bisa berpikir dewasa dalam membangun rumah tangga. Ibu akan mempunyai anak pertama pada saat berumur 23-30 tahun karena pada umur tersebut resiko yang dialami ibu saat hamil dan melahirkan lebih sedikit (Wati, 2014).

Umur 25-36 bulan adalah masa toddler, pada umur ini ibu masih khawatir dengan kesehatan anaknya, sehingga ibu tetap membawa anaknya ke Posyandu untuk menimbang berat badan dan memantau pertumbuhan serta perkembangan anaknya (Fitri, 2015). Hal ini sama dengan hasil penelitian Asdhany (2012), tentang hubungan tingkat partisipasi ibu dalam kegiatan Posyandu dengan status gizi anak balita, didapatkan bahwa mayoritas umur anak yang berkunjung ke Posyandu yaitu umur 24-59 bulan $(71 \%)$.

\section{b. Jenis kelamin}

Hasil penelitian menunjukkan mayoritas responden anak berjenis kelamin laki-laki sebanyak 204 orang $(53,4 \%)$. Data dari Puskesmas Payung Sekaki tahun 2016, dari 8300 anak balita (1-5 tahun) lebih banyak berjenis kelamin laki-laki daripada perempuan 
yakni laki-laki sebanyak 4344 orang dan perempuan sebanyak 3956 orang, sehingga anak yang lebih banyak datang ke posyandu berjenis kelamin laki-laki. Hal ini sama dengan hasil penelitian Handini (2013), tentang hubungan tingkat pendapatan keluarga dengan status gizi balita, didapatkan hasil bahwa mayoritas responden yaitu berjenis kelamin laki-laki $(56,9 \%)$.

\section{c. Pendidikan}

Hasil penelitian menunjukkan mayoritas pendidikan responden ibu yaitu SMA sebanyak 325 orang $(85,1 \%)$. Hal ini sama dengan hasil penelitian Yogiswara (2011), tentang hubungan antara tingkat partisipasi ibu di Posyandu dengan status gizi balita, juga didapatkan mayoritas pendidikan responden yaitu pendidikan SMA (70\%). Hasil penelitian Shulhaeni (2016), tentang hubungan pendidikan orang tua dengan status gizi balita, didapatkan bahwa ada hubungan antara pendidikan orang tua dengan status gizi balita.

Ibu berpendidikan SMA meyakini pentingnya membawa anak berkunjung ke Posyandu dalam memantau pertumbuhan, perkembangan, status gizi, dan pentingnya pelayanan kesehatan (Maryunani, 2010). Hasil penelitian ini didapatkan mayoritas responden ibu berpendidikan SMA dengan ibu bekerja sebagai Ibu Rumah Tangga (IRT), sehingga mereka punya waktu luang untuk membawa anaknya ke Posyandu.

\section{d. Pekerjaan}

Hasil penelitian menunjukkan mayoritas pekerjaan responden yaitu Ibu Rumah Tangga (IRT) sebanyak 347 orang (90,8\%). Hal ini sama dengan hasil penelitian Asdhany (2012), tentang hubungan tingkat pastisipasi ibu dalam kegiatan Posyandu dengan status gizi anak balita, didapatkan bahwa mayoritas pekerjaan responden yaitu tidak bekerja $(83,9 \%)$.

Kegiatan Posyandu yang dilakukan pada pagi hari sehingga kebanyakan ibu yang mengunjungi Posyandu berstatus tidak bekerja. Ibu yang bekerja, terikat oleh jam kerja sehingga ibu tidak dapat membawa balitanya ke Posyandu pada hari jam kerja. Ibu yang tidak bekerja mempunyai waktu luang lebih besar dalam memberikan perhatian kepada anaknya dengan membawa anaknya ke Posyandu (Maulana, 2013).

\section{e. Pendapatan keluarga}

Hasil penelitian menunjukkan mayoritas pendapatan responden yaitu 500.0001.500.000 sebanyak 235 orang (61,5\%). Pendapatan keluarga 500.000-1.500.000 termasuk golongan pendapatan rendah (Badan Pusat Statistik, 2014). Pendapatan keluarga rendah mungkin belum bisa mencukupi kebutuhan nutrisi anaknya seperti protein, karbohidrat, lemak, mineral, vitamin, dan air yang sangat penting dalam proses pertumbuhan dan perkembangan. Kebutuhan nutrisi sangat penting bagi anak, apabila kebutuhan tersebut kurang terpenuhi maka akan dapat mempengaruhi berat badan anak (Hidayat, 2009). 
Wahyudi Diagama', Yufitriana Amir ${ }^{2}$, Yesi Hasneli ${ }^{3}$, Hubungan Jumlah Kunjungan Posyandu dengan Status Gizi Balita (1-5 Tahun)

\section{f. Kunjungan ke Posyandu}

Hasil penelitian menunjukkan bahwa responden yang tidak membawa anaknya berkunjung ke posyandu sebanyak 237 orang (62\%) dan yang rutin mengunjungi Posyandu sebanyak 145 orang (38\%). Penelitian ini lebih banyak responden ibu tidak membawa anaknya ke posyandu dikarenakan beberapa masalah yakni kurangnya fasilitas kesehatan yang ada di posyandu, kurangnya kualitas pelayanan kesehatan di posyandu, dan kurangnya kegiatan dari Puskesmas sehingga ibu tidak tertarik untuk datang membawa anaknya ke posyandu. Hal ini diperkuat dengan penelitian Handayani (2012) tentang hubungan kualitas pelayanan kesehatan posyandu dengan frekuensi kunjungan ibu balita ke posyandu, didapatkan $p$ value $(0,00)$ ada hubungan antara kualitas pelayanan kesehatan posyandu dengan frekuensi kunjungan ibu balita ke posyandu.

\section{g. Status gizi balita}

Hasil penelitian menunjukkan status gizi responden yaitu gizi baik sebanyak 203 orang $(53,1 \%)$. Hasil penelitian ini didapatkan responden ibu yang tidak rutin mengunjungi posyandu memiliki gizi baik sebanyak 103 orang $(43,5 \%)$ hampir sama dengan yang rutin ke posyandu sebanyak 100 orang $(69,0 \%)$. Ibu yang tidak rutin ke posyandu menyebabkan berat badan anak tidak terpantau dengan baik, sehingga masih ditemukan anak berstatus gizi kurang dan status gizi buruk. Hal ini dapat dicegah apabila ibu rutin ke posyandu karena Ibu akan diberikan penyuluhan terkait kesehatan ibu dan anak oleh tenaga kesehatan dari Puskesmas, sehingga dapat meningkatkan pemahaman ibu tentang status gizi, pertumbuhan dan perkembangan anaknya (Kementerian Kesehatan RI, 2012).

\section{h. Hubungan jumlah kunjungan Posyandu dengan status gizi balita (1-5 tahun)}

Hasil penelitian menunjukkan bahwa responden yang rutin mengunjungi Posyandu memiliki gizi baik sebanyak 100 orang $(69,0 \%)$ dan responden yang tidak rutin mengunjungi Posyandu memiliki gizi baik sebanyak 103 orang (43,5\%). Hasil uji statistik didapatkan $p$ value $(0,00)$ maka Ho ditolak, sehingga dapat disimpulkan ada hubungan jumlah kunjungan posyandu dengan status gizi balita (1-5 tahun) ( $p$ value $<a)$.

Hal ini diperkuat dengan hasil penelitian Octaviani dkk (2008), tentang hubungan keaktifan keluarga dalam kegiatan Posyandu dengan status gizi balita, didapatkan bahwa ada hubungan antara keaktifan keluarga ke Posyandu dengan status gizi balita ( $p$ value 0,00). Penelitian Tunjungsari (2010), tentang hubungan antara keaktifan kunjungan ibu ke Posyandu dengan perkembangan status gizi anak usia 6-23 bulan, didapatkan bahwa keaktifan kunjungan ibu ke posyandu juga mempengaruhi status gizi anak ( $p$ value 0,02 ).

Partisipasi ibu harus ditingkatkan dalam upaya untuk mengurangi masalah gizi buruk pada anak dengan mengunjungi dan menimbang balitanya ke Posyandu setiap bulan (Kementerian Kesehatan RI, 2015). Kerutinan ibu dalam mengunjungi posyandu 
akan sangat bermanfaat sebagai monitoring berat badan untuk mengetahui status gizi anak dengan menimbang berat badan setiap bulan agar dapat secara dini mendeteksi status kesehatan anak, sehingga dapat segera ditentukan intervensi lebih lanjut. Apabila ibu tidak secara rutin mengunjungi posyandu mengakibatkan status gizi anak tidak terpantau dengan baik (Astuti \& Rivqoh, 2010).

\section{SIMPULAN}

Setelah dilakukan penelitian tentang hubungan jumlah kunjungan posyandu dengan status gizi balita (1-5 tahun), diketahui responden ibu yang diteliti mayoritas berumur pada rentang 26-35 tahun sebanyak 327 orang $(85,6 \%)$. Responden anak mayoritas berumur pada rentang 25-36 bulan sebanyak 184 orang $(48,2 \%)$ dengan berjenis kelamin laki-laki sebanyak 204 orang (53,4\%). Responden ibu mayoritas berpendidikan SMA sebanyak 325 orang $(85,1 \%)$ dengan status pekerjaan sebagai IRT sebanyak 347 orang $(90,8 \%)$. Pendapatan keluarga dalam sebulan 500.000-1.500.000 sebanyak 235 orang $(61,5 \%)$ dengan anak gizi baik sebanyak $203(53,1 \%)$.

Responden ibu yang tidak membawa anaknya berkunjungan ibu ke posyandu sebanyak 237 orang (62\%) dan yang rutin mengunjungi posyandu sebanyak 145 orang (38\%). Responden yang rutin mengunjungi posyandu mempunyai gizi baik sebanyak 100 orang $(69,0 \%)$ dan responden yang tidak rutin mengunjungi posyandu mempunyai gizi baik sebanyak 103 orang (43,5\%). Hasil uji statistik didapatkan $p$ value $(0,00)$ maka Ho ditolak, sehingga dapat disimpulkan ada hubungan jumlah kunjungan posyandu dengan status gizi balita (1-5 tahun).

\section{SARAN}

1. Pengembangan Ilmu Keperawatan

Hasil penelitian ini diharapkan dapat menambah wawasan dan pengetahuan tentang hubungan kunjungan posyandu dengan status gizi balita (1-5 tahun).

2. Posyandu

Hasil penelitian ini diharapkan dapat menjadi tambahan informasi bagi kader bahwa posyandu dapat memantau status gizi pada balita melalui penimbangan berat badan yang rutin di posyandu.

3. Puskesmas

Hasil penelitian ini diharapkan menjadi informasi bagi tenaga kesehatan yang ada di Puskesmas agar bisa melakukan pelatihan serta penyuluhan kepada kader posyandu, sehingga dapat meningkatkan pengetahuan para kader tentang kesehatan, pengelolaan Posyandu dengan baik, dan pemantauan status gizi anak.

\section{Masyarakat}

Hasil penelitian ini diharapkan dapat menjadi informasi bagi masyarakat khususnya ibu yang memiliki balita agar lebih aktif dalam kegiatan posyandu setiap bulannya untuk memantau status gizi anak dengan penimbangan berat badan yang rutin sehingga dapat menurunkan kejadian gizi buruk. 
Wahyudi Diagama', Yufitriana Amir ${ }^{2}$, Yesi Hasneli ${ }^{3}$, Hubungan Jumlah Kunjungan Posyandu dengan Status Gizi Balita (1-5 Tahun)

\section{Peneliti Selanjutnya}

Hasil penelitian ini diharapkan dapat menjadi bahan informasi dalam melakukan penelitian selanjutnya tentang posyandu dan status gizi balita dan dapat melanjutkan penelitian ini untuk lebih mengembangkan penelitian dalam mengetahui kunjungan posyandu terhadap perkembangan dan pertumbuhan balita dilihat dari tinggi badan berdasarkan umur anak dan berat badan berdasarkan tinggi badan.

\section{DAFTAR PUSTAKA}

Annisa, K. (2014). Pintar membaca growth chat anak dan kurva pertumbuhan WHO. Dunia Sehat. Diperoleh tanggal 20 Januari 2017 dari http://duniasehat.net/2014/09/12/.

Asdhany, C. (2012). Hubungan tingkat partisipasi ibu dalam kegiatan posyandu dengan status gizi anak balita. Jawa Tengah: Universitas Diponegoro. Jurnal Diponegoro University. Diperoleh pada tanggal 19 Juli 2017 dari http://eprints.undip.ac.id/.

Astuti, I., \& Rivqoh. (2010). Hubungan pengetahuan ibu tentang posyandu dengan keteraturan ibu mengunjungi posyandu didesa Cibeber RW 14 Puskesmas Cibeber Cimahi. Jawa Barat: Stikes A. Yani Cimahi. Jurnal Kesehatan Kartika. Diperoleh pada tanggal 05 Mei 2017 dari http://stikesayani.ac.id/.

Badan Kependudukan dan Keluarga Berencana Nasional. (2017). Usia pernikahan ideal. BKKBN. Diperoleh tanggal 24 Juli 2017 dari http://bkkbn.go.id/detailpost/.

Briawan, D. (2012). Optimalisasi posyandu dan posbindu dalam upaya perbaikan gizi masyarakat. Pembekalan KKP Ilmu Gizi. Diperoleh tanggal 16 Desember 2016 dari http://fema.ipb.ac.id/wpcontent/uploads/2012/05/.
Dewi, A. B. F. K., Pujiastuti, N., \& Fajar, I. (2013). Ilmu gizi untuk praktisi kesehatan. Yogyakarta: Graha Ilmu.

Dinas Kesehatan Provinsi Bali. (2013). Meningkatkan kesehatan ibu dan anak melalui gerakan posyandu. Dinas Kesehatan Provinsi Bali. Diperoleh tanggal 13 Desember 2016 dari http://www.diskes.baliprov.go.id/id/Artike 13.

Dinas Kesehatan Provinsi Jawa Tengah. (2013). Profil kesehatan Provinsi Jawa Tengah. Semarang: Dinas Kesehatan Provinsi Jawa Tengah.

Dinas Kesehatan Provinsi Riau. (2014). Profil kesehatan Provinsi Riau. Pekanbaru: Dinas Kesehatan Provinsi Riau.

Dinas Kesehatan Provinsi Riau. (2015). Profil kesehatan Provinsi Riau. Pekanbaru: Dinas Kesehatan Provinsi Riau.

Fitri, A. W. G. (2015). Peran kelompok bermain dalam proses sosialisasi anak usia dini di Kecamatan Sukorejo Kabupaten Kendal. Semarang: Universitas Negeri Semarang. Journal Digilib Unnes. Diperoleh pada tanggal 07 Juli 2017 dari http://lib.unnes.ac.id/.

Handayani, R. N. (2012). Hubungan antara kualitas pelayanan kesehatan posyandu dengan frekuensi kunjungan ibu balita ke posyandu XI Serangan Sidoluhur Godean Sleman Yogyakarta. Yogyakarta: Sekolah Tinggi Ilmu Kesehatan 'Aisyiyah. Jurnal Unisa. Diperoleh pada tanggal $12 \mathrm{Juli}$ 2017 dari http://opac.unisayogya.ac.id/.

Handini, D. (2013). Hubungan tingkat pendapatan keluarga dengan status gizi balita di wilayah kerja Puskesmas Kalijambe. Jawa Tengah: Universitas Muhammadiyah Surakarta. Jurnal UMS $E T D-d b$. Diperoleh pada tanggal 08 Juli 2017 dari http://eprints.ums.ac.id/.

Hidayat, A. A. A. (2007). Riset keperawatan dan teknik penulisan ilmiah edisi kedua. Jakarta: Salemba Medika.

Hidayat, A. A. A. (2009). Pengantar ilmu keperawatan anak. Jakarta: Salemba Medika.

Istiany, A., \& Rusilanti. (2013). Gizi terapan. Bandung: PT Remaja Rosdakarya. 
Kementerian Kesehatan RI. (2011). Pedoman umum pengelolaan posyandu. Jakarta: Kementerian Kesehatan RI.

Kementerian Kesehatan RI. (2011). Standar antropometri penilaian status gizi anak. Jakarta: Kementerian Kesehatan RI.

Kementerian Kesehatan RI. (2012). Buku panduan posyandu, posyandu menjaga anak dan ibu tetap sehat. Kementerian Kesehatan RI Pusat Promosi Kesehatan. Diperoleh tanggal 16 Desember 2016 dari http://promkes.depkes.go.id/.

Kementerian Kesehatan RI. (2015). Profil kesehatan Indonesia. Jakarta: Kementerian Kesehatan RI.

Maryunani, A. (2010). Ilmu kesehatan anak dalam kebidanan. Jakarta: Trans Info Media.

Maulana, A. (2013). Hubungan keaktifan ibu dalam posyandu dengan penurunan jumlah balita Bawah Garis Merah (BGM) di desa Suko Jember Kecamatan Jelbuk Kabupaten Jember. Jawa Timur: Universitas Jember. Jurnal Universitas Jember. Diperoleh pada tanggal 11 Juli 2017 dari http://repository.unej.ac.id/handle/

Notoatmodjo, S. (2012). Metodologi penelitian kesehatan. Jakarta: Rineka Cipta.

Nursalam. (2008). Konsep dan penerapan metodologi penelitian ilmu keperawatan: Pedoman skripsi, tesis, dan instrumen penelitian edisi 2. Jakarta: Salemba Medika.

Nursalam., Susilaningrum, R., \& Utami, S. (2008). Asuhan keperawatan bayi dan anak. Jakarta: Salemba Medika.

Octaviani, U., Juniarti, N., \& Mardiah, A. (2008). Hubungan keaktifan keluarga dalam kegiatan posyandu dengan status gizi balita di desa Rancaekek Kulon Kecamatan Rancaekek. Bandung: Universitas Padjadjaran. Jurnal Unpad. Diperoleh pada tanggal 14 Juli 2017 dari http://repository.unpad.ac.id/.

Purba, E. H. B. (2012). Faktor yang berhubungan dengan prilaku kunjungan ke posyandu pada ibu balita di wilayah kerja Puskesmas Pancoran Mas Kota Depok. Jawa Barat: Universitas Indonesia. Skripsi. Diperoleh pada tanggal 04 Juli 2017 dari http://lib.ui.ac.id/.
Puspitasari, I. (2015). Faktor-faktor yang mempengaruhi pertisipasi ibu balita ke posyandu Kencusari di Dukuh Tegaltandan desa Banguntapan Kabupaten Bantul. Yogyakarta: Sekolah Tinggi Ilmu Kesehatan Aisyiyah Yogyakarta. Skripsi. Diperoleh pada tanggal 25 Juni 2017 dari http://opac.unisayogya.ac.id/.

Setiadi. (2013). Konsep dan praktik penulisan riset keperawatan edisi 2. Yogyakarta: Graha Ilmu.

Shulhaeni, H. F. N. (2016). Hubungan antara pendidikan orang tua dan status gizi balita di desa Ngargosari Kecamatan Samigaluh Kabupaten Kulon Progo Yogyakarta. Jawa Tengah: Universitas Muhammadiyah Surakarta. Jurnal UMS ETD-db. Diperoleh pada tanggal 08 Juli 2017 dari http://eprints.ums.ac.id/.

Sujarweni, V. W. (2014). Metode penelitian keperawatan. Yogyakarta: Gava Media.

Sulistyawati, A. (2014). Deteksi tumbuh kembang anak. Jakarta: Salemba Medika.

Sulistyoningsih, H. (2011). Gizi untuk kesehatan ibu dan anak. Yogyakarta: Graha Ilmu.

Sulistyorini, C. I. (2010). Posyandu (Pos Pelayanan Terpadu) dan desa siaga. Yogyakarta: Nuha Medika.

Susanti, E. (2016). Hubungan tingkat ekonomi keluarga dan pengetahuan ibu tentang status gizi balita dengan status gizi balita di Posyandu Subur Kelurahan Pulai Anak Air wilayah kerja Puskesmas Nilam Sari Bukittinggi. Sumatera Barat: Sekolah Tinggi Ilmu Kesehatan Prima Nusantara. Jurnal Prima Nusantara. Diperoleh pada tanggal 15 Mei 2017 dari http://ejurnal.stikesprimanusantara.ac.id/.

Swarjana, K. (2012). Metodologi penelitian kesehatan. Yogyakarta: Andi.

Tunjungsari, D. M. (2010). Hubungan antara keaktifan kunjungan ibu ke posyandu dengan perkembangan status gizi anak usia 6-23 bulan. Jawa Timur: Universitas Jember. Jurnal Universitas Jember. Diperoleh pada tanggal 07 Juli 2017 dari http://repository.unej.ac.id/handle/.

Wati, I. K. (2014). Faktor-faktor yang berhubungan dengan minat ibu terhadap kunjungan ke Posyandu di Kelurahan 
Wahyudi Diagama', Yufitriana Amir ${ }^{2}$, Yesi Hasneli ${ }^{3}$, Hubungan Jumlah Kunjungan Posyandu dengan Status Gizi Balita (1-5 Tahun)

Kembangarum Kota Semarang tahun 2014. Semarang: Sekolah Tinggi Ilmu Kesehatan Ngudi Waluyo Ungaran. Skripsi. Diperoleh pada tanggal 03 Juli 2017 dari http://perpusnwu.web.id/.

Yogiswara, B. A. (2011). Hubungan antara tingkat partisipasi ibu di posyandu dengan status gizi balita. Jawa Tengah: Universitas Diponegoro. Jurnal Diponegoro University. Diperoleh pada tanggal $10 \quad$ Juli 2017 dari http://eprints.undip.ac.id/. 